\title{
Nursing diagnoses for the elderly using the International Classification for Nursing Practice and the activities of living model ${ }^{1}$
}

\author{
Ana Claudia Torres de Medeiros ${ }^{2}$ \\ Maria Miriam Lima da Nóbrega ${ }^{3}$ \\ Rosalina Aparecida Partezani Rodrigues ${ }^{4}$ \\ Maria das Graças Melo Fernandes ${ }^{5}$
}

Objective: To develop nursing diagnosis statements for the elderly based on the Activities of Living Model and on the International Classification for Nursing Practice. Method: Descriptive and exploratory study, put in practice in two stages: 1) collection of terms and concepts that are considered clinically and culturally relevant for nursing care delivered to the elderly, in order to develop a database of terms and 2) development of nursing diagnosis statements for the elderly in primary health care, based on the guidelines of the International Council of Nurses and on the database of terms for nursing practice involving the elderly. Results: 414 terms were identified and submitted to the content validation process, with the participation of ten nursing experts, which resulted in 263 validated terms. These terms were submitted to cross mapping with the terms of the International Classification for Nursing Practice, resulting in the identification of 115 listed terms and 148 non-listed terms, which constituted the database of terms, from which 127 nursing diagnosis statements were prepared and classified into factors that affect the performance of the elderly's activities of living - 69 into biological factors, 19 into psychological, 31 into sociocultural, five into environmental, and three into political-economic factors. Conclusions: After clinical validation, these statements can serve as a guide for nursing consultations with elderly patients, without ignoring clinical experience, critical thinking and decision-making.

Descriptors: Nursing/classification; Terminology; Aging; Elderly; Nursing Diagnosis.

\footnotetext{
1 Paper extracted from Master's Thesis "Diagnósticos/Resultados e Intervenções de Enfermagem para idosos: Proposta de Subconjunto Terminológico da CIPE" presented to Centro de Ciências da Saúde, Universidade Federal da Paraíba, João Pessoa, PB, Brazil. This research was supported by Programa Nacional de Coordenação Acadêmica (PROCAD-NF/CAPES), process \# $2428 / 2008$. 2 MsC, Doctoral Student, Universidade Federal da Paraíba, João Pessoa, PB, Brazil.

${ }^{3}$ PhD, Associate Professor, Centro de Ciências da Saúde, Universidade Federal da Paraíba, João Pessoa, PB, Brazil.

${ }^{4}$ PhD, Full Professor, Escola de Enfermagem de Ribeirão Preto, Universidade de São Paulo, WHO Collaborating Centre for Nursing Research Development, Ribeirão Preto, SP, Brazil.

${ }^{5}$ PhD, Professor, Centro de Ciências da Saúde, Universidade Federal da Paraíba, João Pessoa, PB, Brazil.
} 


\section{Introduction}

In general, the elderly population faces multidimensional problems that affect their health and, consequently, their quality of life. Therefore, elderly care delivery requires a comprehensive, interdisciplinary and multidimensional approach that contributes to their capacity to develop strategies to age with the highest possible level of quality and minimal problems for them and their families. From this perspective, primary health care has been developing towards a comprehensive care focus, particularly with regard to the elderly, which helps to control a variety of health issues and substantially contributes to improve their quality of life(1).

The primary health care model requires healthcare professionals' knowledge about the multidimensionality of the aging process. In this context, Professional Nursing Activity has been developing towards new horizons and more humanized perspectives in elderly care. It is essential that nursing actions are guided by the understanding that the aging process is marked by specific changes that require professional abilities to deal with the different situations these demands entail(2).

This new population scenario has also created the need to reorganize nursing care, based on a scientific method that is aimed at improving the quality of care. Therefore, Professional Nursing has made use of this method in an individual and dynamic way, based on technical and scientific knowledge. This has been increasingly mentioned, at times as systematization of nursing care and, at other times, as the nursing $\operatorname{process}^{(3)}$.

In this study, Nursing Care Systematization (NCS) and the nursing process are considered distinct concepts, in accordance with COFEN Resolution 358/2009(4), according to which NCS is defined as the organization of professional work with regard to method, personnel and instruments, which permits the operationalization of the nursing process, considered a methodological instrument that guides professional nursing care and is organized into five interrelated, interdependent and recurrent stages: nursing data collection (or nursing history); nursing diagnosis; nursing planning; implementation; nursing evaluation. When developed in primary health care, it is called nursing consultation and should have a theoretical framework to guide the development of its stages $^{(4)}$.

In Professional Nursing, there are different theories and conceptual models that attempt to explain the health promotion and education processes. In this study, the "Activities of Living Model" was chosen, developed by the nurses Roper, Logan and Tierney, and consists of the following components: activities of living, factors that affect activities of living, degree of dependence/independence and individuality of living(5). The use of this model is intended to provide Professional Nursing with a framework for planning an individualized approach at all levels of activities of living for clients at more advanced ages and who are at home and assisted in primary healthcare.

It is noteworthy that, for the structure and evolution of care in Professional Nursing, the use of nursing classification systems has become essential, particularly the use of the International Classification for Nursing Practice $\left(\text { ICNP }^{\circledR}\right)^{(6)}$, which promotes the technological and scientific development of this profession. Such classification promotes professional recognition, resulting from the registration and quality of care practice, especially when targeted at specific nursing care areas, represented by the INCP $^{\circledR}$ terminological subgroups and consisting of sets of nursing diagnosis statements, outcomes and interventions.

In view of the above, this study is aimed at developing nursing diagnosis statements for the elderly, based on the Activities of Living Model and on the ICNP ${ }^{\circledR}$, with a view to supporting the development of a special language to be used in Professional Nursing at the primary healthcare level.

\section{Method}

This study is part of the research project "ICNP ${ }^{\circledR}$ terminology subgroups for clinical specialty and primary healthcare areas", which is under development in the Graduate Nursing Program at UFPB, and "Condition of life, health and the aging process: a comparative study", funded by the National Academic Coordination Program (PROCAD), which is being developed by the Federal University of Paraiba and the University of São Paulo at Ribeirao Preto College of Nursing (EERP-USP), referred to as the "main project" in this study. The project is undertaken in the city of João Pessoa, Paraíba state, and involves elderly people living at home.

The study was carried out after gaining approval from the Research Ethics Committee at the Federal University of Paraiba University Hospital Lauro Wanderley, under registration CEP/ HULW number 034/11. The completion of this study demanded two stages: 1) collection of terms and concepts that are considered clinically and culturally relevant for elderly 
nursing care; and 2) development of nursing diagnosis statements for the elderly.

For the first stage, a documentary and descriptive study with a quantitative approach was carried out, in which the concepts contained in the structured instrument of the main project were identified, considered clinically and culturally relevant for the development of nursing diagnosis statements, and therefore important for elderly nursing care. This instrument consisted of five parts: 1) Socio-demographic classification of the elderly; 2) Mini-Mental State Examination (MMSE); 3) Self-referred health issues; 4) Edmonton Frailty Scale (EFS); and 5) Instrumental Activities of Daily Living Scale (IADLs).

Initially, several readings of the instrument were done in order to identify the relevant terms for nursing practice, and these terms were then separated into simple terms (nouns, verbs, adverbs and adjectives), which resulted in a list of 414 terms that, after undergoing a standardization and uniformization process to remove repetitions, correct spelling, analyze synonyms and adjust of gender and number, resulted in 298 terms.

These terms were included in a form to be submitted to content validation by a group of ten nursing experts who were participating in the main project and who agreed to participate in the study and signed the Informed Consent Form. They were asked to judge the clinical and cultural relevance of these terms to develop nursing diagnosis statements for the elderly. To process the data collected in the survey, the incoming forms were numbered and the terms that reached an acceptance rate of $\geq 0.49$ among the participants were considered as validated.

The 263 validated terms were subject to the cross-mapping technique with the terms of the Seven Axes Model of ICNP ${ }^{\circledR} 2011^{(6)}$. To perform the mapping, spreadsheets were created in Excel for Windows, which were subsequently imported into Access for Windows, in order to prepare tables of terms identified in the study and ICNP ${ }^{\circledR}$ terms. After crossing these two tables, 115 terms listed and 148 terms not listed in this terminology were identified, which turned into the Database of Terms for Nursing Practice in relation to primary healthcare to the elderly.

For the development of nursing diagnosis statements, the Database of Terms for Nursing Practice in relation to primary healthcare to the elderly and the ICN guidelines, which determine the mandatory inclusion of terms from the Focus and Judgment Axes, besides the additional terms from the other axes, were used as needed ${ }^{(7)}$. The statements developed were classified according to the theoretical model related to the factors and activities of living.

\section{Results}

The Database of Terms for Nursing Practice in relation to primary healthcare to the elderly consisted of 263 terms, 115 of which were considered terms listed and 148 terms not listed in the ICNP ${ }^{\circledR}$. The 263 terms were distributed according to the ICNP ${ }^{\circledR}$ Seven Axes Model. Thus, 12 belonged to the Action axis, 15 to the Client axis, 149 to the Focus axis, 26 to the Judgment axis, 12 to the Location axis, 35 to the Means axis and 10 to the Time axis.

Based on these terms and the ICN guidelines, 127 nursing diagnosis statements were developed and related to the biological, psychological, socio-cultural, environment and political-economic factors, which affect the elderly's performance of their activities of living (Table 1). These statements were discussed according to the activities of living.

Table 1 - Frequency distribution of nursing diagnosis statements according to the factors that affect the elderly's activities of living. João Pessoa, PB, Brazil, 2011

\begin{tabular}{|c|c|c|}
\hline \multirow{2}{*}{$\begin{array}{l}\text { Factors that affect activities of } \\
\text { living }\end{array}$} & \multicolumn{2}{|c|}{$\begin{array}{l}\text { Nursing diagnosis } \\
\text { statements }\end{array}$} \\
\hline & $\mathbf{N}$ & $\%$ \\
\hline Biological & 69 & 54.3 \\
\hline Psychological & 19 & 15.0 \\
\hline Socio-cultural & 31 & 24.4 \\
\hline Environmental & 5 & 3.9 \\
\hline Political-economic & 3 & 2.4 \\
\hline Total & 127 & 100.0 \\
\hline
\end{tabular}

The results showed that most diagnosis statements $(78.7 \%)$ were related to the biological and sociocultural factors, with emphasis on the anatomical and physiological aspects of the elderly and the cultural, religious, ethical aspects and the role and relationship of the elderly with their families and the community. The psychological, environmental and political aspects were also contemplated with nursing diagnosis statements, which reveals the possibility that the elderly are attended in relation to all factors that affect the activities of living.

\section{Discussion}

The nursing diagnosis statements, classified into the factors mentioned, show the following activities of 
living: Maintaining a safe environment, Breathing, Eating and Drinking, Elimination, Communication, Washing and dressing, Working and playing, Mobilization, Expressing sexuality, Sleeping and Dying.

The activity of living Maintaining a safe environment helps with the elderly's performance of activities to prevent accidents at their homes, such as fire, electric shock, among others. Therefore, it is considered a preventive activity. In everyday life, people seek to perform activities that somehow contribute to preserve a safe environment, almost without conscious effort, although it is part of daily tasks. Examples of safety measures are those that avoid domestic accidents and those to protect against fire ${ }^{(5)}$.

The decline in activities of living as a result of reduced physical and intellectual capacity intensifies the need to maintain safer environments (regular floors, ramps, appropriate lighting, grab bars in bathrooms, handrails), in order to minimize the risks of accidents that often lead to situations of disability and dependence among the elderly. However, the risk of elderly people who are afraid of falling to have a fall is greater when their activities are restricted ${ }^{(8)}$. The results permitted the development of nursing diagnosis statements related to Maintaining a safe environment: Polluted environment; Damaged property condition; Dysfunctional stress caused by change of environment; Fall; Risk of stress caused by change of environment; Risk of lack of security in the physical environment; Risk of injury; Risk of falling; Risk of domestic violence; and Evident domestic violence.

"Breathing" is the first activity of a person and is considered an act that is part of life. Consequently, activities of living totally depend on breathing. During the aging process, the conditions that limit a person's breathing ability increase, due to the lung adjustment in relation to the increase or release of a sufficient amount of carbon dioxide ${ }^{(9)}$, leading to an increased mortality rate ${ }^{(10)}$. Signs like dyspnea, shortness of breath, blood gases, abnormal arteries, cyanosis, closed lip breathing, retraction of the respiratory muscles during breathing and superficial breathing are indicative of the nursing diagnosis Ineffective breathing pattern, which was the only statement developed in the study for this activity of living.

The activity of living "Eating and Drinking" is central to the promotion, preservation and/or recovery of health in all stages of life. There is no doubt about its impact on the health status and functional capacity, even if the physical need for basic nutrients is the same during all stages of life ${ }^{(5)}$. Morphological, functional, behavioral and psychological changes that gradually occur during the aging process, often associated to pathophysiological and pharmacological aspects, may progressively prevent this age group from maintaining a good nutritional status. These negative changes directly affect food intake and nutritional absorption and can even lead to malnutrition ${ }^{(11)}$.

Regarding the activity of living "Eating and drinking", the following nursing diagnosis statements were developed: Impaired swallowing; Impaired dentition; Excess weight; Hyperglycemia; Impaired food intake; Appropriate body weight; Increased body weight; and Reduced body weight. As a result of the aging process, the senses of taste and smell decrease, and chewing capacity, peristalsis, sensation of hunger and salivary secretion are also reduced, involute changes occur in the teeth and gums, hydrochloric acid secretion is reduced, the peristaltic contractions in the stomach are decreased and the capacity to absorb nutrients is lost, which affect the nutritional status. During this process, people may lose interest in preparing and eating meals and, in this stage of life, teeth loss, influenced by culture, inappropriate nutrition and changes in the gums also contribute to several food restrictions, which can result in changes to the nutritional status ${ }^{(9,12-13)}$.

In the study, the following nursing diagnosis statements for the activity of living Elimination were developed: Diarrhea; Constipation; Appropriate urinary elimination; Impaired urinary elimination; Bowel incontinence; Urinary Incontinence; Risk of urgency urinary incontinence; Urinary retention; and Risk of constipation.

"Elimination" is another essential activity of living, as its purpose is to expel the substances resulting from organic catabolism. With the aging process, structural alterations of the detrusor muscle, such as the development of fibroses and hypersensitivity to noradrenaline, result in reduced bladder capacity and development of involuntary contractions, which cause symptoms of urinary urgency and/or urinary incontinence. At any age, urinary incontinence depends not only on the anatomical integrity of the lower urinary tract and on the mechanisms involved in urine storage and elimination, but also on cognitive capacity, mobility and motivation to go to the toilet(14).

As age advances, changes occur in the digestive system, including decreased stomach motility, gastric mucosal atrophy and decreased number of cells in the absorptive surface of the intestinal walls. However, aging 
by itself does not cause constipation, which results from a combination of the following risk factors: general health conditions, nutritional aspects, physical exercise, medication use ${ }^{(9,15)}$.

The activity of living Communication promotes interpersonal interaction and relationship among people. It can therefore take various forms ${ }^{(5)}$. The act of communicating consists of sharing information contents, thoughts, ideas and wishes with someone else. For this to happen, common codes are used. Communication is essential to the life of human beings ${ }^{(16)}$. The communication and interaction nurses establish with the elderly and their families are means of intervention par excellence, not only to restore communication and interaction of the elderly with other people, but also as a way of diagnosing and identifying the difficulties the elderly experience.

For this activity, the following nursing diagnosis statements were developed: Effective family support; Impaired verbal communication; Impaired concentration; Acute confusion; Chronic confusion; Conflicting religious belief; Availability for effective decision making; Availability for facilitating religious belief; Lack of family support; Effective memory; Impaired memory; Effective temporal and spatial orientation; Impaired temporal and spatial orientation; Damaged family relationship; Satisfactory family relationship; Risk of conflicting religious belief; Risk of loneliness; and Loneliness.

Washing and Dressing are activities related to each person, especially depending on culture. Regardless of these factors, when performed correctly and conveniently, they can prevent several diseases. Dressing is a significant activity that causes psychological wellbeing to the person, as it is often used as a way to adapt to environmental and social needs. Dressing and undressing are actions that require a lot of coordination, dexterity, balance, extensive movement and muscle strength and, as these functions are generally affected by the aging of the musculoskeletal system, it is common for the elderly to have difficulty in performing them ${ }^{(17)}$. For this activity of living, the following nursing diagnosis statements were developed: Impaired ability to perform care; Impaired ability to have a shower; Impaired ability to use the toilet; Effective ability to dress/undress and grooming; Impaired ability to dress/ undress and grooming; Satisfactory ability to carry out personal hygiene; Effective ability to carry out oral hygiene; Inability to carry out personal hygiene; and Damaged oral mucosa.
Working is the main activity of an adult and is part of the construction of a person's social identity. It is how people produce their means of life, through which livelihood is provided, existential feelings are created, or which contribute to structure the personality and strengthen the identity. The human being develops and prepares for work and also needs it, not only as a matter of survival, but also for personal growth(18) and social inclusion.

As work is predominantly the main source of income in a person's adult life, leisure and social activities are highly important to promote good selfesteem and self-achievement in the elderly, especially after the abrupt changes caused by retirement ${ }^{(19)}$. For the elderly, working increases their life expectancy, provides wellbeing, increases interests, which keep them healthier, performing responsibility roles, and contributes to increase self-esteem and prevents feelings of worthlessness and impairment. Besides, there is the possibility to contribute to family income, since living with three generations is part of the elderly's lives, and their retirement income would not be sufficient to meet the financial needs of the home.

Based on the results, the following nursing diagnosis statements related to Working and Playing were developed: Impaired leisure activity; Impaired ability to perform housework; Ability to make the finances; Lack of participation in social and community activities; Insufficient family income; Insufficient personal income; and Caregiver's activity overload.

The activity of living Mobilization is part of all other activities. Therefore, any damages to mobilization affect all, biological, psychological, sociocultural and political-economic levels of a person, which in turn affect the autonomy/independence to perform other activities of living(5). Among several changes resulting from the aging process, the ones relating to the motor activity, such as muscular and skeletal weakening, decreased motor coordination and balance, loss of muscle mass and decreased muscle tone can be highlighted(17). The reduction of the muscle strength in the elderly's lower limbs may result in increased instability and the consequent risk of falls and dependence. Intrinsically to this risk, the fear of falling down is created, which entails negative consequences for the physical and functional wellbeing of the elderly, loss of independence, decreased ability to perform activities of daily living and restricted physical activity. This almost always justifies the elderly's sedentary lifestyle ${ }^{(8)}$. 
It is imperative, therefore, to understand how the aging process causes incapacity and disability among the elderly, since they are determined not only by health/illness conditions, but also by cultural aspects, social and environmental contexts and availability of services $^{(20)}$, often associated to the senility process. Professional Nursing should help to minimize their limitations and strengthen their abilities with a view to keeping them active and interested in their daily activities. Therefore, it should contribute to maintain them capable and independent (physically and mentally). The nursing diagnosis statements developed in this study relating to the activity of living Mobilization were: Access to effective healthcare service; Access to ineffective healthcare service; Effective walking; Impaired walking; Daily life activities attended to; Daily life activities not attended to; Impaired ability to carry out shopping; Satisfactory ability to carry out shopping; Effective ability to prepare food; Impaired ability to prepare food; Effective ability to move; Impaired ability to move; Effective ability to take care of the house; Impaired health-seeking behavior; Satisfactory healthseeking behavior; Sedentary lifestyle; Lack of capacity to manage exercise routine; Lack of knowledge about physical exercise; Physical activity intolerance; Impaired health maintenance; Impaired pace; Impaired physical mobility; Lack of adherence to exercise; and Impaired exercise patterns.

Sexuality is a vital function that permeates all stages of human development. Each person has a unique way of expressing his/her sexuality, based on the manner they were allowed to and according to their culture. The elderly experience the sexuality that has been socially developed throughout their lives. Sexual behavior is determined by multiple principles, such as culture, religion and education, which hinder its expression(21-22). Some health problems can cause limitations but, in most cases, do not prevent the elderly from having an active sexual life ${ }^{(21)}$. Although the frequency and intensity of sexual activity can change throughout life, problems related to the ability to feel pleasure during sexual relations should not be considered as a normal part of aging(23). Concerning the activity of living Expressing sexuality, the following nursing diagnosis statements were developed: Sexual dysfunction and Ineffective sexual patterns.

As for the activity of living Sleeping, the nursing diagnosis statements Effective sleeping patterns and Dysfunctional sleeping were developed. The changes that occur during the aging process affect the quality of sleep and rest, causing damages to the health of the elderly. Therefore, nurses need to identify the aspects that contribute to poor sleep quality, with the purpose of planning effective interventions, aimed at improving the quality of life(24).

The activity of living Death is the last stage of the life cycle. Death can be understood in different ways, depending on the culture and beliefs of the elderly, but each person has his/her own way of experiencing it. Aging by itself entails a universal fear that leads to increasing fear of death, causing disruptions and demanding adjustments in the way of perceiving the world and making plans to continue living in it ${ }^{(25)}$. In this study, the following nursing diagnosis statements were developed in relation to the activity of living "Death": Anxiety; Death anxiety; Improved anxiety; Low selfesteem; Hopelessness; Fear; Fear of death; and Chronic sadness.

As regards the activity of living Controlling temperature, listed in the Activities of Living Model, no nursing diagnosis statements were developed. This fact drew attention because, through this capacity, it is possible to maintain biological processes related to the metabolism and which contribute to the promotion of personal wellbeing, taking into consideration temperature variations across the various environments where the elderly may live. Although the body selfregulates its temperature, the human being is, at times, obliged to develop activities that avoid the risks heat or cold cause ${ }^{(5)}$. When reviewing the instrument used in this study, in search of an answer that explains this fact, it was noted that there are no terms in the instrument that lead to the development of statements involving body temperature. This fact should be corrected before continuing the research.

\section{Conclusion}

As a result of a continuous and intense aging process of the population, knowledge about the peculiarities resulting from human aging becomes imperative. Therefore, it is also a Professional Nursing responsibility to ensure that the elderly are able to maintain healthy habits and that their limitations, in detriment of life, are reduced and compensated for.

The study objectives were achieved, resulting in the development of 127 nursing diagnosis statements, with the aim of providing a tool that facilitates elderly care delivery and, consequently, putting the nursing care systemization in practice through nursing consultations 
at the primary healthcare level. It is further considered that the theoretical model used, - Activities of Living Model - which supported the nursing diagnosis statements, is broad but also flexible, clear, coherent, and can be applied to primary healthcare for the elderly in Professional Nursing.

The results of this study also show that further studies need to be carried out to validate the contents of the nursing diagnosis statements, as a way to permit the integration between scientific and practical knowledge, as well as to clinically validate these statements, which should be tested through clinical case studies, involving the elderly participants of the main project, in order to verify their applicability and the use of a unified language to document elderly nursing care at the primary healthcare level in the city of Joao Pessoa - PB.

\section{References}

1. Portella MR. Atenção integral no cuidado familiar do idoso: desafios para a enfermagem gerontológica no contexto da estratégia saúde da família. Rev Bras Geriatr Gerontol. 2010;13(3):501-6.

2. Pinheiro GML, Alvarez AM, Pires DEP. A configuração do trabalho da enfermeira na atenção ao idoso na Estratégia de Saúde da Família. Ciênc Saúde Coletiva. 2012;17(8):2105-15.

3. Garcia TR, Nóbrega MML. Classificação Internacional para a Prática da Enfermagem: inserção brasileira no projeto do Conselho Internacional de Enfermeiras. Acta Paul Enferm. 2009;22(n. esp):875-9.

4. Conselho Federal de Enfermagem (BR). Resolução COFEN no 358, de 15 de outubro de 2009: dispõe sobre a sistematização da assistência de enfermagem e a implementação do processo de enfermagem em ambientes públicos ou privados, em que ocorre o cuidado profissional de Enfermagem, e dá outras providências. Brasília (DF); 2009.

5. Roper N, Logan W, Tierney A. The Roper, Logan, Tierney Model of Nursing based on activities of living. London: Churchill Livingstone; 2000.

6. International Council of Nurses [Internet]. International Classification for Nursing Practice: Version 2011. [acesso 8 marzo 2012]; Disponível em: http:// icnp.clinicaltemplates.org/icnp/download/.

7. Internacional Council of Nurses. International Classification for Nursing Practice - Version 1. Geneva, Switzerland: International Council of Nurses; 2005.

8. Martin FC, Hart D, Spector T, Doyle DV, Harari D. Fear of falling limiting activity in Young-old women is associated with reduced functional mobility rather than psychological factors. Age and Ageing. 2005;34(3):281-7.

9. Eliopoulos C. Enfermagem gerontológica. 7a ed. Porto Alegre: Artmed; 2011.

10. Ruivo S, Viana P, Martins C, Baeta C. Efeito do envelhecimento cronológico na função pulmonar. Comparação da função respiratória entre adultos e idosos saudáveis. Rev Port Pneumol. 2009;15(4):629-53.

11. Silva JV. Saúde do idoso e a Enfermagem: processo de envelhecimento sob múltiplos aspectos. São Paulo: Iátria; 2009.

12. Marucci MFN, Mercúrio R. Metabolismo do idoso. Nutrição Profissional. 2005;3:14-9.

13. Dias BKP, Cardoso MCAF. Características da função de deglutição em um grupo de idosas institucionalizadas. Estud Interdiscipl Envelhecim. 2011;14(1):107-24.

14. Virtuoso JF, Mazo GZ, Menezes EC. Prevalência, tipologia e sintomas de gravidade da incontinência urinária em mulheres idosas segundo a prática de atividade física. Fisioter Mov. 2012;25(3):571-82.

15. César MAP, Klug WA, Aguida HAC, Ortiz JA, Fang $C B$, Capelhuchnik P. Alterações das pressões anais em pacientes constipados por defecação obstruída. Rev Bras Colo-Proctol. 2008;28(4):402-8.

16. Sousa MGC, Russo ICP. Audição e percepção da perda auditiva em idosos. Rev Soc Bras Fonoaudiol. 2009; 14(2):241-6.

17. Araújo LAO, Bachion MM. Diagnósticos de enfermagem do padrão mover em idosos de uma comunidade atendida pelo Programa Saúde da Família. Rev Esc Enferm USP. 2005;39(1):53-61.

18. Bulla LC, Kaefer CO. Trabalho e aposentadoria: as repercussões sociais na vida do idoso aposentado. Texto Contexto-Enferm. 2003;2(2):1-8.

19. Gáspari JC, Schwartz GM. O idoso e a ressignificação emocional do lazer. Psicologia: Teoria e Pesqui. 2005;21(1):69-76.

20. Farias N, Buchalla CM. A classificação internacional de funcionalidade, incapacidade e saúde da Organização Mundial da Saúde: conceitos, usos e perspectivas. Rev Bras Epedemiol. 2005;8(2):187-93.

21. Almeida T, Lourenço ML. Envelhecimento, amor, e sexualidade: utopia ou realidade. Rev Bras Geriatr Gerontol. 2007;10(1):101-13.

22. Gradim CVC, Sousa AMM, Lobo JM. A prática sexual e o envelhecimento. Cogitare Enferm. 2007;12(2):204-13. 23. Ministério da Saúde (BR). Secretaria de Atenção à Saúde. Departamento de Atenção Básica. Envelhecimento e saúde da pessoa idosa. Ministério da Saúde: Brasília; 2007.192 p. 
24. Cunha MCB, Zanetti ML, Hass VJ. Sleep quality in type 2 diabetics. Rev. Latino-Am. Enfermagem. 2008;16(5):850-5.

25. Silva CAS, Carvalho LS, Santos ACPO. Vivendo após a morte de amigo: história oral de idosos. Texto Contexto-Enferm. 2007;16(1):97-104. 